\title{
Strategic Analysis and Knowledge Support Systems (SAKSS): Translating Evidence into Action
}

\author{
Michael E. Johnson
}

\section{Introduction}

Many sub-Saharan African countries today have committed to the continent-wide goals of the Comprehensive African Agriculture Development Programme (CAADP) of the Africa Union and New Partnership for Africa's Development (NEPAD). The goals draw attention towards a shared commitment of allocating at least $10 \%$ of their national budgets to agriculture in order to achieve a $6 \%$ annual sector growth rate and meet the Millennium Development Goal (MDG) of halving poverty by 2015. As a result, policymakers have been called on to allocate more resources and design strategies to accelerate agricultural growth in order to meet these goals. The challenge now is ensuring that selected policies and investment strategies are effective in producing their intended goals of sustaining broad-based growth and poverty reduction.

The desire for more effective policy and investment strategies that translate into the achievement of shared CAADP goals has revived questions about capacities for policy analysis and participatory processes of designing and implementing development strategies in Africa. Many past studies in the region have documented the failure of past central planning or top down approaches of implementation (Brinkerhoff 1996; Crosby 1996; Killick 1976; Montjoy and O’Toole 1979; Wildavsky 1973). Such inadequacies led to calls for more decentralized, evidence-based, and participatory processes, to be complemented by strong monitoring and evaluation (M\&E) systems that allow for adaptation to changing conditions over time given the nonlinear and dynamic nature of designing and implementing development strategies.

\footnotetext{
M.E. Johnson ( $\bowtie)$

CARE USA, Washington, DC, USA

e-mail: mjohnson@care.org

C. Henning et al. (eds.), Development Policies and Policy Processes in Africa, 
Recognizing the complexities of formulating and implementing effective policies and investment strategies requires a lot of evidence to accurately assess the choices available to a government and the tradeoffs inherent in any choice they make. ${ }^{1}$ To supply this evidence, the country must have a solid foundation of analytical capacity throughout its planning agencies and academic institutions. In addition, governments need policymakers who have the motivation and ability to demand and use the information (Omamo 2004). The intersection of these two sides and the knowledge generated describes the state of a national knowledge system, defined here as the existing stock of knowledge and established links between people and organizations on both the supply and demand side in influencing the type of knowledge products generated and utilized in policy dialogue and decisionmaking.

How effective a national knowledge system is in generating and promoting the use of evidence depends on many factors: the perceived credibility and relevance of the evidence generated; the type of relationships and linkages that develop among all individual actors and organizations involved; capacities to comprehend and utilize the evidence, the local policy process and political climate; and local beliefs and norms (Young 2005; Cash et al. 2003). Often, it is the linkage among individuals and organizations that help to bridge the supply and demand for evidence which is especially weak. It requires establishing effective mechanisms by which both sides can be more closely tied as part of ongoing dialogue and decisionmaking processes. These mechanisms effectively link suppliers and users of knowledge through the creation and use of knowledge products.

For many African countries, the state of their national knowledge systems remains very weak and poses a serious challenge for strengthening the effectiveness of future strategy design and implementation efforts. Data collection and analysis continues to suffer from a shortage of attention and resources. Knowledge sharing is often minimal, with planning ministries that operate in isolation and uncoordinated ministries, research institutes, and statistical bureaus. Government agencies, NGOs, and development partners carry out parallel and overlapping processes of information gathering. Often development partners have more input into the strategy process than legislative bodies or the national civil society does. The M\&E frameworks of many strategies rarely deal with issues of causality and attribution between investments, policy changes, and outcomes.

The large capacity gaps also exacerbated an inherently weak link between the supply and demand of evidence. For example, local universities rarely undertake research directly relevant to local decisionmaking needs while national institutions and agencies seldom have sufficient capacities and experience to provide relevant information needed to guide strategy formulation and implementation.

\footnotetext{
${ }^{1}$ By evidence we mean data statistics and analysis of past trends, economic analysis of future policy alternatives, impact assessment of past investments, research findings from a number of disciplines (public policy, socioeconomic and political sciences, and the biophysical sciences), and lessons from practice and experience.
} 
The Strategic Analysis and Knowledge Support System (SAKSS) concept was developed in direct response to these serious capacity gaps in many African countries. Its principle goals are to: (a) bring quality and strategic analysis to bear on identifying key investments, institutional mechanisms, and policy options, as well as the implementation of selected options for agricultural policy and investment strategies (this includes harmonizing and generating standardized information for development planning and $\mathrm{M} \& \mathrm{E}$, and to be available as global public goods); (b) build and strengthen national and regional capacities for policy analysis, M\&E, while helping to bridge the research and policy divide; and, (c) broker the dialogue and links between institutions and individuals who supply and use data and information related to agricultural strategies by establishing network for information exchange and knowledge management.

The SAKSS was developed around two key concepts-'strategic analysis' and 'knowledge support systems' which have since defined its overall purpose and utility for supporting CAADP implementation. The 'strategic analysis' concept describes generating information that is not only scientifically credible but has important relevance to the range of questions and issues being faced by policymakers in formulating and implementing their country's agricultural development strategies. The 'knowledge support system' concept defines a network of individuals and institutions that are linked in ways intended to help bring strategic analysis and research evidence to bear during the design and implementation of the agricultural development strategy. We now review these in more detail.

\section{The Strategic Analysis Concept and Approach}

Strategic analysis describes a logical series of analyses which help identify policy and investment options for achieving growth and poverty outcomes, beginning with a broader, economywide perspective and ending with a more targeted sector and community level perspective. This type of integrated analysis is intended to guide a credible action plan of development priorities in agriculture which contribute the most to the achievement of desirable targets for growth and poverty reduction. Such prioritization implies finding answers to a range of strategic questions such as: What is the role of agriculture in promoting overall economic growth and poverty reduction in the different stages of development given a country's natural resource endowments? How should public resources be mobilized and allocated among different sectors, sub-sectors, and regions? What have been the lessons and effect of agricultural policies and investments on outcomes and impact? Answers to these questions can help arm policymakers with useful evidence on the kinds of tradeoffs and outcomes associated with their policy and investment choices.

The analysis is considered 'strategic' so long as it contributes to the narrowing down of investment options that will help lead to the achievement of these high-end development targets. It means weighing in the costs and benefits for undertaking one strategy over another. For example, should government focus on promoting a 
rapid expansion in food staples production? It will definitely benefit consumers, but producers could be devastated if prices drop too fast following a bumper harvest. Or, governments may wish to introduce a policy that is designed to target the poor and yet undercuts private sector participation and long term sustainability, such as in the case of output procurement and the provision of modern inputs.

The sequence and types of analysis are not fixed, however. Different local contexts may require a different set of analyses. Because SAKSS has been primarily developed for African countries with a large agricultural sector, the analysis is focused on identifying options for agriculture as a source of economic growth and poverty reduction. Various economic tools and methodologies exist, but which tools and approaches are used will not only depend on the question being asked but on many other important considerations as well, such as: the availability of data and expertise, time to undertake the analysis, cost, access to analytical tools and economic models, and underlying assumptions and limitations. Johnson and Flaherty (2011) provide a review of some of these tools, as well as a guidance on which tool is most appropriate under what conditions with respect to a range of factors such as data availability, cost, and time to complete the analysis.

To illustrate, we offer a number of very broad but logically sequenced series of 'strategic analysis' type questions to consider when assessing the policy and investment alternatives for achieving goals of agricultural growth and poverty reduction. These include: How can agriculture contribute the most to overall development objectives? How should resources be mobilized and allocated more efficiently? How can individual policies and interventions be better targeted? How can lessons be monitored and evaluated during and after implementation? We review each of these below.

\subsection{How Can Agriculture Contribute the Most to Overall Development Objectives?}

From the outset, it is useful to first establish the country's current situation and whether its trajectory will lead to the achievement of the CAADP goals. It should do so within the context of the country's overall economy in order to highlight a broad set of strategic options and tradeoffs - e.g. whether simply promoting faster growth is more important than considering poverty and food security, or even environmental degradation. This context is needed because policies at the macro level, such as trade and market liberalization, can have a profound impact on growth, and even more so on agriculture, the rural economy, and poverty (Dorward et al. 2004). At the same time, policies that directly affect rural areas and agriculture can have an impact on the overall economy and in turn have feedback effects on the rural sector. By examining many of these policy options within the context of the broader economy, key relationships and welfare implications can be assessed in ways that lessen any potential adverse impacts on the poor. 
The economywide perspective permits other higher-level strategic questions to be posed for shaping an agricultural strategy within the context of overall national development goals, and in so doing, provides the greatest strategic leverage to priority setting (Byerlee 2000). The potential role of agriculture, including individual subsectors in agriculture, can then be explored with respect to how they contribute to economywide growth and national development priorities, such as reducing poverty. Within this normative mode of analysis, questions regarding the long-term distributional consequences of alternative investment and policy choices for meeting these targets can also be explored. Specific to rural sector strategies, sectorwide investment options should be examined more closely, especially with regard to how they affect the incentives for rural agricultural production and commercialization.

Various economic analysis tools can be used. For example, the Computable General Equilibrium (CGE) model is particularly well suited for analyzing a country's progress towards achieving its national development goals through agriculture. CGE models help analyze the effects of policy shifts and alternative sector growth scenarios on overall economic growth and poverty reduction. They have the advantage of capturing both direct and indirect effects of policy changes on poverty and income distribution given a country's overall economic structure. The effects are channeled through changes in employment, wages and relative prices while considering forward and backward linkages in the economy. From this, policymakers can weigh the costs and benefits associated with focusing attention on stimulating growth in different sectors and subsectors.

Existing examples that apply this level of analysis involve the work that has been undertaken by IFPRI researchers in a number of countries in Africa (e.g. Ethiopia, Ghana, Mozambique, Rwanda, Zambia and Malawi). From these studies, for example, it became quickly evident that most countries could not meet the MDG poverty target of halving poverty by 2015, with the exception of Ghana, Mozambique and Uganda. Model results further showed that the additional growth would need to be driven mostly by food staple sectors as these have a larger impact on poverty reduction than similar growth in export-oriented crops (see example for Zambia in Fig. 1). This impact occurs because yield improvements in food crops not only benefit households directly, by increasing incomes from agricultural production, but also by allowing farmers to diversify into higher-value crops. Food crops also typically have stronger growth-linkages to non-agriculture, which stimulates broader economywide growth and poverty reduction.

\subsection{How Should Resources Be Mobilized and Allocated More Efficiently?}

An essential component of a development strategy is its plan for prioritizing investments and mobilizing resources. A strategy grounded in country-specific 
Zambia will surely miss MDG-1

+ agric. export diversification remains difficult

+ northern regions remain very poor

Narrow agricultural sector and high yield gaps for major crops (esp. non-maize food crops)

Agrological diversify requires regional strategy (e.g. root crops for northern farmers)

Priority: Maize (strong growth \& poverty effects) Roots (poverty effects for poorest population)

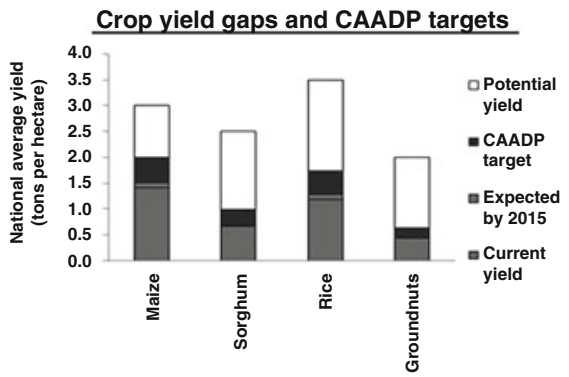

Ranking crops \& subsectors

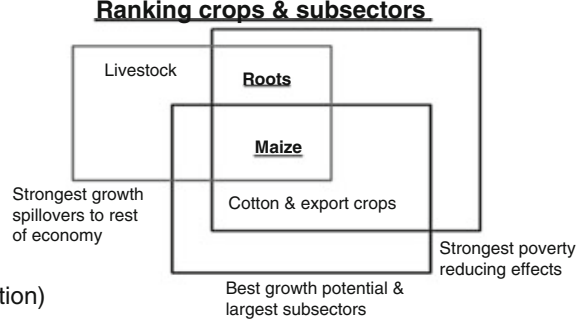

Poverty reduction under CAADP

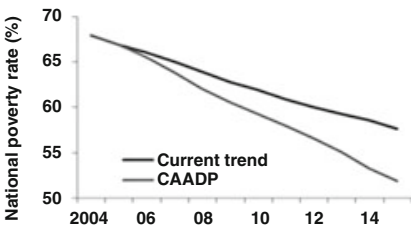

Fig. 1 Example of 'strategic analysis' results of investment options for Zambia. Source: CAADP Modeling results from Thurlow et al. (2008b)

context must be based on a thorough assessment of the public investment situation and potential to contribute to the development goals. Public investments can be thematic (e.g. roads, marketing institutions), sectorwide (e.g. research and extension, irrigation), and subsector specific (e.g. commodity-based research).

All these investments affect rural poverty through many channels. For example, public investment in agricultural research, rural education and health, and infrastructure increases farmers' income directly by increasing agricultural productivity and lowering transaction costs of both inputs and outputs, which in turn reduces rural poverty. Indirect impacts come from higher agricultural wages and improved nonfarm employment opportunities induced by growth in agricultural productivity and increases in market opportunities. Growth in agricultural output from rural investment often yields lower food prices, again helping the poor indirectly because they are often net buyers of food crops. Redistribution of land caused by higher agricultural growth also has important impacts on rural poverty. In addition to their productivity impact, public investments in rural education, health, and infrastructure directly promote rural wages, nonfarm employment, and migration, thereby reducing rural poverty. For example, improved infrastructure access will help farmers set up small nonfarm businesses in rural areas such as food processing and marketing enterprises, electronic repairs shops, transportation and trade, and restaurant services. A key underlying assumption is that public and private investments are complements (Anderson et al. 2006), so that an increase in public goods and accumulation of capital stock raises the productivity of all factors in agricultural production, which in turn leads to higher farm wages and incomes and poverty reduction. 
Investments in the rural sector not only contribute to growth, more employment opportunities, and higher wages in rural areas, but also help the development of the national economy by providing labor, human and physical capital, cheaper food, and markets for urban industrial and service development. This type of growth in the national economy can then help reduce poverty in both rural and urban sectors. Understanding these different effects provides useful policy insights to improve the effectiveness of government poverty reduction strategies. In particular, it provides information on how public investment can be used to strengthen links between poverty reduction channels to increase efficiency in targeting public resources on poverty reduction. More efficient targeting has become increasingly important in an era of macroeconomic reforms in which governments are under pressure to reduce budgets. For examples of tools and approaches to measure the impact of investments, see Appendix A.5 and Benin et al. (2008b).

The question of how resources should be mobilized and allocated across the different economic sectors and geographic regions is essentially answering a range of high-end questions that inform the design and evaluation of a development strategy, such as: (a) What have been the trends of government expenditures by sector, and what have been the reasons for their changes? (b) How has public investment been financed, and how has the burden of financing investment policy been distributed in society? (c) What have been the economic rates of return to various types of government expenditures, including their impact on growth and poverty reduction? (d) What level of effort in public spending is required to achieve targeted goals for agriculture and overall economic growth?

Analyzing these series of questions not only helps identify the kinds of public sector investments which offer the highest economic rate of return (for an example, see Fan et al. 2004 for Uganda), but they also help assess the extent to which past investments have impacted on overall development goals (a topic covered next). It requires sufficient subnational data on the level and distribution of public sector expenditures and investments over time. A public expenditure review is especially useful as a first step in compiling the required data. It will also help determine the extent to which actual resource allocations are consistent with a country's strategy and goals. Combining this information with other data, such as household survey data on consumption, production, and welfare measures, will allow for more sophisticated analyses. For example, using econometric tools, more detailed analysis can be carried out, drawing on the cross-sectional variation of the data, to measure and attribute differences in outcome variables such as growth and poverty to the accumulated stock of past investments and other socioeconomic variables. Where time series data are also available on the same cross-sectional data, the dynamics and lagged effects of public investments can also be analyzed. When combined with independent estimates of the unit costs of different investments, cost/benefit ratios can be calculated.

Results from the econometric analysis can be further translated into unitless elasticity estimates. An elasticity measures the sensitivity or marginal effect of a $1 \%$ change in one variable on the percent change in another variable. For example, an expenditure-to-growth elasticity would measure the effect of a $1 \%$ change in the 
stock of investments (or expenditures) on the change in growth outcomes, whether at the sector or economywide level. This becomes useful for estimating future growth requirements in public investments for generating desired sector and economic growth targets. Using estimates of both an expenditure-to-growth elasticity and a growth-to-poverty elasticity, one can then estimate the level of resources required to achieve desired growth and poverty goals (see Fan et al. 2008). A number of country case studies that have estimated resource requirements for meeting the CAADP goal of $6 \%$ include Benin et al. (2008a) and Thurlow et al. (2008a, b).

\subsection{How Can Individual Policies and Interventions Be Better Targeted?}

Many of the challenges and opportunities that national development strategies must negotiate are geographic in nature and affect different communities on the ground. For example, economic opportunities can vary widely by location depending on other important factors such as the natural resource base (e.g. agriculture potential), population density, and access to markets and rural services (e.g., education, health, agriculture extension). Development options would be quite different for more remote and food insecure areas versus those areas located in close proximity to large market centers. Thus any interventions should be specifically targeted towards the unique characteristics of the area and depending on the severity of the problem-such as quantifying the extent and distribution of poverty and malnutrition across geographic areas and population groups is an important first step (Babu and Pinstrup-Andersen 1994).

With the increasing availability of spatially disaggregated data and tools to understand those data, it has become increasingly possible to map indicators of biophysical and socioeconomic indicators showing local comparative advantage for different agricultural and rural development options (see example of Uganda in Fig. 2 below). Agroclimatic factors, access to markets, and population density are some of the more important dimensions for assessing agricultural development potential (Pender et al. 2001). By viewing how these conditions correlate and overlap each other spatially with local welfare measures, assumptions can be made about how different development investments will impact the poor and how changing agricultural land uses may have environmental costs. Taken together, these conditions provide an enhanced picture of the costs and benefits of different investments, allowing better targeting towards the goals of sustainable growth, poverty reduction, and environmental sustainability (see Wood and Chamberlin 2003; Wood et al. 1999).

Taking on a spatial perspective helps to seek answers associated with targeting interventions. For example, a range of questions it may help answer include: (a) What are the distribution and extent of income, poverty and malnutrition across 


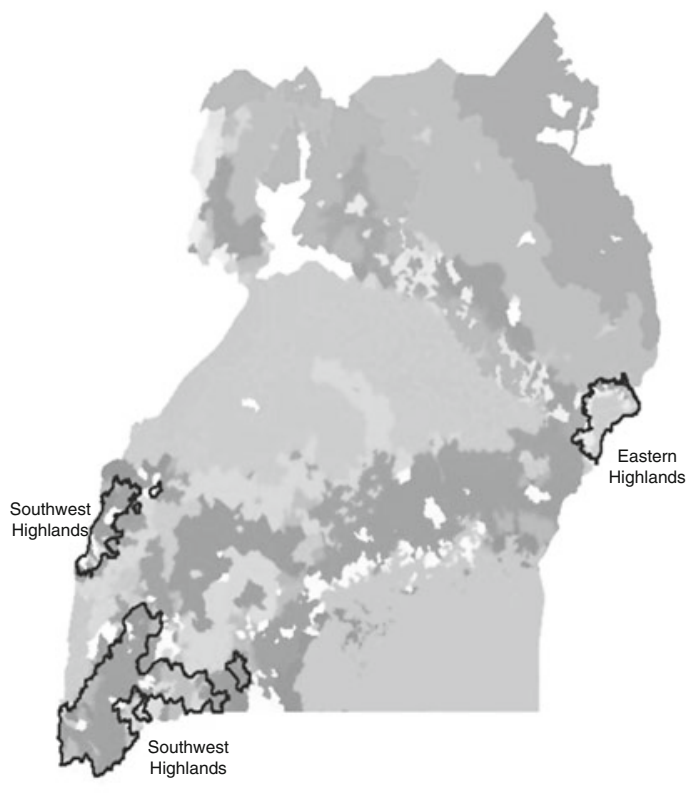

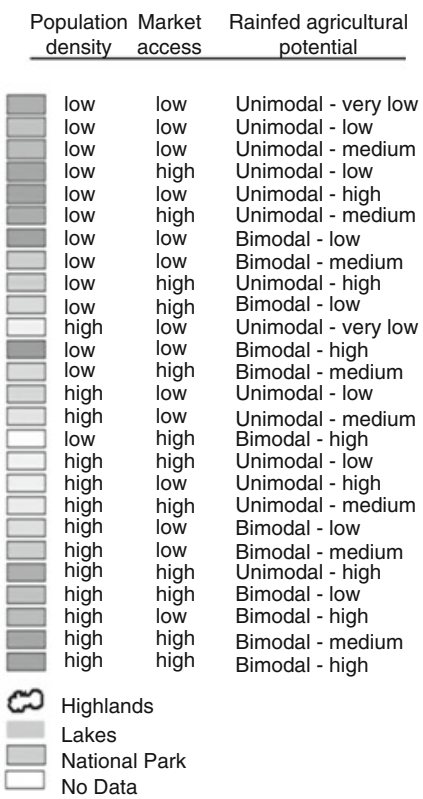

Fig. 2 Mapping out development domains in Uganda. Source: Johnson and Flaherty (2011)

different locations in the country? (b) What kinds of opportunities and challenges affect rural economic livelihoods in different parts of the country? (c) For agriculture, what are the key development domains based on agriculture potential, market access and population density? (d) Which development domains offer the greatest potential for high investment impact among the key subsectors and economic activities identified as key sources of growth in the economywide analysis above? (e) What kinds of interventions (e.g. infrastructure, R\&D and extension, institutional) are needed to spur productivity and income growth among select domains? (f) Among the poorest of the domains, in terms of limited resource assets and livelihood options, what are the alternatives for poverty reduction and food security?

Exploring answers to these questions can be answered with tools such as Geographic information Systems (GIS) and remote sensing. Having access to spatially oriented data, including agroclimatic conditions, land-use, production, urban and markets centers, infrastructure, household consumption, and welfare, is particularly critical but often lacking in many African countries. However, with increasing sophistication of computer technologies and satellite imagery, filling in some of the gaps is increasingly possible. For example, You et al. (2007) recently used a cross-entropy approach to make plausible allocations of crop production by small square grids (or pixels) based on available statistics of larger subnational units and satellite imagery. 
A number of examples illustrate the usefulness and application of spatial analysis for targeting investments in agriculture. At the country level, useful examples include the work undertaken by Pender et al. (2001) and Bolwig et al. (2002) for mapping out development domains in Uganda. The more recent work by Chamberlin et al. (2006) builds on this concept. At the regional level, the studies by Omamo et al. (2006) and Johnson et al. (2008) are especially noteworthy. Spatial analysis tools were complemented by various economic analyses to assess future agricultural growth options and research priorities in the Eastern and Western regions of sub-Saharan Africa.

\subsection{How Can Lessons Be Monitored and Evaluated During and After Implementation?}

A critical part of any agricultural strategy is to be able to determine at some point whether the strategy is on track to achieving its goals, or whether at the end of its life, people's lives have been positively or negatively impacted on. It helps to justify resource investments and ensure accountability. It also provides the option to adjust the strategy as new evidence becomes available on what has (or has not) been working. From the perspective of the goals of SAKSS, therefore, helping to provide credible and relevant analysis and information related to $M \& E$ is a fundamental prerequisite to promoting evidence-based policymaking. And although the importance of M\&E systems is well-documented (see for example, Mackay 2007 and Dalal-Clayton and Bass 2002), it is often the most difficult part to set up and maintain. This is because agricultural strategies operate within a broader and complex environment that is inherently dynamic with respect to constantly changing domestic and global economic conditions, social and political trends, climatic shocks, and participatory and political processes associated with designing and implementing policies and investment strategies.

Ultimately, therefore, an M\&E system seeks to answer questions that determine whether development objectives are being fulfilled and if there is impact in order to help revise and improve futures strategies, such as: (a) Is the allocation and level of inputs (e.g. spending, investments, policy interventions) of the agricultural strategy (or project) on target? (b) How can the impact of these investments be traced to improvements in outputs (e.g. productivity, viability of production systems, food processors, agro-industries, markets, and trade)? (c) Have these improvements affected outcomes (e.g. incomes and the poverty status of target populations)? (d) What factors have shaped (positively and negatively) the level of impact achieved to date? What needs to be altered? (e) What was the distribution of these intermediate impacts, e.g. on smallholders, on equity, on gender, on other spillover impacts? (f) Are there key ingredients of success or failure based on past experience and lessons learned? What role for public versus private sector? 
A desirable $M \& E$ system is one that can encompass not only the monitoring of progress among key inputs, outputs and outcome indicators, but evaluates the magnitude and distribution of impact. For the former, simple descriptive narratives of trends among the indicators help to answer the adequacy question: "have expectations in terms of investment flows and achievement of the growth and poverty reduction targets been met so far?" However, it does not answer the key hypotheses on: "how effectively have different types of policies and investments impacted on the goals so far?" and "what factors have shaped the level of impact that has been achieved?" These last two questions are more concerned with the evaluation or impact assessment part of M\&E. Addressing all three provides key information that can help guide decisions on what to adjust, as well as the scale and mix of investment priorities needed, in order to keep a country's agricultural strategy on track. In this way, it is a critical component of the strategic analysis agenda of a SAKSS, by coming full circle to helping inform and strengthen future design and implementation of agricultural strategies.

In order to find answers to questions a good M\&E system seeks to provide, there are three challenges facing many African countries: the availability and quality of data from national statistical systems from which to gather baseline information and set future targets; having a clear $M \& E$ framework in place that describes the interrelationships (or causality) between inputs, outputs and outcomes; and integral to the development of the M\&E framework itself, having in place sufficiently robust methods and tools for evaluating impact over time.

\subsubsection{Ensuring Availability and Reliability of Underlying Data Systems}

The poor availability of reliable data in most African countries makes it particularly challenging for setting up a national M\&E system, just as it is for the other types of strategic analyses discussed in this chapter. Especially problematic is the frequency of data collection and quality on agricultural production and marketing. Most African countries have only undertaken a handful of these surveys since the 1970s. In Ghana, for example, the last comprehensive agricultural census was carried out in the early 1970s followed by a smaller sampled survey in 1986. Other socioeconomic surveys, such as the living standards measurement surveys (LSMS), population and housing census, and demographic and health surveys (DHS) have occurred more frequently, but these vary across countries.

Even if there is data available, its quality is often poor due to overall weak technical and managerial capacities of national statistical systems. Explanations for this have included a generally low regard for statistical information by policymakers; poor links between statistical systems and policy processes; inadequate government spending and technical assistance for statistics over long periods of time; and outdated statistical systems and legislation (Kiregyera 2008; Wingfield-Digby 2007). Another weak data area is having timely and sufficient information on the flows of public sector expenditures and investments in agriculture-especially from public expenditure tracking surveys or PETS (Dorotinsky 
and Floyd 2004). Such information can serve as key input for setting baselines and targets for investment spending and for undertaking impact studies later on, in addition to helping improve accountability and public sector management more generally. Typically, much of this information is found within finance ministries, with details of agricultural expenditures available from the sector ministry.

There are increasing efforts to improve data systems for agriculture in general for many African countries (see Kiregyera 2008). One recent effort being led by the World Bank is the Living Standards Measurement Study and Integrated Surveys on Agriculture (LSMS-ISA) to improve household level panel data on agriculture in sub-Saharan Africa. According to the World Bank's website on this initiative, six African countries will initially benefit from this. In time, and once scaled out to other countries, this should help improve and complement existing data sets for purposes of monitoring performance and impact of ARD strategies in Africa. Another is the introduction of the AU/NEPAD budgetary tracking system for agricultural expenditures to monitor the national compliance of the Maputo declaration. This has begun to make information on total agriculture spending available (AU/NEPAD 2005). However, because it doesn't cover disaggregate flows by subsector and type of investment it is less useful for impact evaluation (see Benin et al. 2010).

\subsubsection{Developing an M\&E Framework}

Simply having sufficient access to data does not guarantee a good M\&E system. It also requires having a credible $\mathrm{M} \& \mathrm{E}$ framework in place, as well as the tools to monitor progress and assess impact. As a start, either a logical or theoretical framework can be useful in this regard. Both seek to layout a simple structure which describes the causal relationship between inputs (e.g. investment flows), outputs (e.g. productivity), and outcomes (e.g. growth and poverty), and from which critical corresponding indicators can be identified for the purpose of monitoring and evaluating impact.

The logical framework (or logframe) approach helps describe a simple flow chart of how inputs will achieve intermediate and final outcomes. Performance indicators are selected as part of a results-oriented log frame matrix, measuring performance in terms of input delivery, implementing activities, producing outputs, and achieving targeted outcomes (World Bank 2004; Kusek and Rist 2004; Crawford and Bryce 2003). The measurement of outputs can also include specifying the extent of coverage among target groups, including non-target groups if spillovers are expected and measurable. Performance indicators are then selected at each stage along a simple causality chain, with assumptions about associated risks and other confounding factors which can influence performance and outcomes. Adaptations to improve the basic logframe have occurred over time by seeking to introduce more participatory approaches and/or theory and analytical rigor along the entire length of the causal chain (White 2006; World Bank 2004). The most 
popular have included the impact chain analysis, outcome mapping, and impact pathway approaches.

Based on the logframe, the impact chain analysis approach essentially maps out the links in the causal chain based on underlying economic theory and evidence. It allows for a more in-depth theoretical understanding of the cause-and-effect relationships or impact pathways between variables and the confounding effects of other potentially influencing factors. And so long as sufficient data exists, empirical evaluations of impact using econometric techniques can also be modeled as discussed further below. Its main disadvantage is that it can easily become unnecessarily complex, data intensive, and costly.

An alternative is the outcome mapping approach, which is more participatory and qualitative in nature, focusing on changes in development processes and outcomes (Earl et al. 2001; Smutylo 2005). Essentially, it identifies expected impacts and outcome indicators based on a map of interrelated factors from intervention to outcomes within a group session. Given the complexity of considering many other noneconomic factors which can influence outcomes, the approach adopts visualization techniques to instill participants to think through the different factors, their direct and indirect effects, as well as causal linkages. This is especially useful for tracing out qualitative changes in development processes which are not easily measurable (e.g. human behavior). A disadvantage of this approach is that it is limited by the complexity of causal relationships that arise as more factors and stakeholders are identified in the process.

More recently, the impact pathway approach was introduced to try and deal with some of the shortcomings of both outcome mapping and impact chain analysis approaches (see Spinger-Heinze et al. 2003 and Douthwaite et al. 2003). The approach recognizes the presence of a number of impact chains and sequences in explaining the overall change process. The analysis of multiple impact pathways can be quite useful for impact evaluation as they avoid the pitfall of assuming a simple linear relationship between an investment and outcome. The analysis of development domains discussed earlier in this chapter, for example, constitutes the existence of multiple but distinct impact pathways. This is because how investments ultimately lead to outcomes depends on the type of combinations among multiple factors - such as agricultural potential, market access and population pressure (Spinger-Heinze et al. 2003; Pender et al. 2001). While it is an improvement, it shares the same drawbacks of outcome mapping and impact chain analysis as it can easily become unnecessarily complex. Additionally, it can quickly become very data intensive and costly when too many other factors and distinct pathways or outcome mappings are introduced.

No matter which approach is adopted, the real challenge from a practical perspective is maintaining sound theory and rigor while at the same time limiting the degree of complexity in drawing out the causality chain and in selecting a minimum set of indicators for which reliable data exists. Depending on the strategy goals and underlying programs, a balance needs to be struck between the need to attribute impact to program interventions and having in place a cost efficient $M \& E$ 
system, one that has the least likelihood for measurement errors and is simple enough to interpret the information that comes out of it.

Despite various approaches to M\&E systems, their basic structure and utility are principally intended to serve as a performance management tool: to help adapt policies and investments during the course of strategy implementation in order to stay on track towards achieving targeted output and outcome goals. An additional advantage of such systems is that they can be developed in a participatory fashion involving broader stakeholder groups. The main drawbacks are that they are less reliable for undertaking a credible impact assessment as they tend to be too static, rigid, and rely only on theoretical assumptions when linking between inputs, outputs and outcomes.

\subsubsection{Undertaking Impact Assessment}

In order to effectively assess the impact of a strategy (or its underlying projects) after it has been in place for some time requires additional tools, both quantitative and qualitative. A number of quantitative tools exist for analyzing impact at the sector or economywide levels and at the project level. The evaluation of sector or economywide impacts of public sector interventions is particularly useful when the goal is to assess effects on aggregate welfare outcomes (e.g. poverty) and their distribution. Where there is sufficient information on past investments and other key factors which influence outcomes, econometric and statistical methods can help test for the contribution of past changes in investments (e.g. agricultural research, infrastructure, health, and education) on changes in outcome variables. This is very much the same approaches described in the previous section on 'How should resources be mobilized and allocated across the different economic sectors and geographic regions?' emphasizing how ex-post impact evaluation is particularly relevant for informing the design of future strategies.

Given the poor availability and quality of data in many African countries, econometric techniques may not be feasible. Under these conditions, simulation and programming models are useful alternatives. For agricultural R\&D, for example, economic surplus models can be used to estimate economic rates of return to investment so long as sufficient information on key technology and behavioral parameters exist (see Alston et al. 1995). Additionally, programming techniques can also be used to estimate changes in agricultural performance (as measured by total factor productivity) that is due to technical change and thus past investments in R\&D (see Farrington et al. 1997). For broader categories of investments, it is also possible to apply economywide simulation models as in the earlier section on 'What are the economywide options for reaching high-end agricultural development goals?' if such models already exist. This can be particularly useful for capturing the impact of broader sectorwide investments on overall economic growth.

The application of economic simulation models to the evaluation of impact after the fact (or ex-post) essentially involves simulating how much an actual change in investments or policy may have affected outcomes. A number of indicators that 
serve as input into the models can be monitored periodically to assess their potential impact on outcomes. As data on outcome variables becomes available, model results can be compared with actual values. If the model predicts an outcome that is below or above the actual observed outcome, it is possible a number of confounding factors could explain the difference, if data and model specification errors are assumed minimal. Results can also be compared against a baseline scenario wherein the intervention is removed to describe a situation 'with and without' - as a type of counterfactual analysis (see example of Bell et al. 1982).

An emerging area is the use of spatial analysis tools for impact assessment. This has become possible as GIS tools, satellite imagery, and computer hardware and software, have advanced over the years. As a result, for example, an increasing number of countries are able to produce high resolution poverty maps. Knowledge of this kind which show disparities in poverty across geographic space, including associated livelihoods and assets, is not only relevant for targeting future investments (as discussed in the section 'How can individual policies and interventions be better targeted?') but can also serve as a monitoring and evaluation tool. Statistical techniques can be applied where there is sufficient data to be able to associate a number of key geographic and socioeconomic factors to changes in welfare over time (e.g. see Minot and Baulch 2005 and Pender et al. 2001).

Impact assessment at the sector or economywide level has its limitations. The effects between investments and outcomes are typically too aggregate to be linked back to any particular intervention (Maredia 2009). The common problem of insufficient data makes econometric and spatial analysis methods difficult and often impractical. While economic simulation models are more feasible under these conditions, their accuracy depends on how well the underlying data, model specification, and behavioral assumptions represent the real world. In many instances, behavioral parameter estimates in a model are drawn from different periods in time and/or different locations.

Impact assessment at the project level, on the other hand, is far more feasible if necessary steps are undertaken from project design to implementation. At this level of analysis, experimental or randomized approaches are more desirable because they can directly test for attribution and causality. This is because randomization allows for measuring impact against some counterfactual or control variable ("before and after," or "with and without," the intervention), while guarding against problems of selection bias in the process. In other words, it can answer questions of how individuals who participated in a program would have fared in the absence of the program, or, how those who were not exposed to the program would have fared in the presence of the program (Duflo et al. 2008; Maredia 2009; White 2006). To ensure sufficient information is collected for randomization, however, early preparations and resources for monitoring and evaluation must be in place when the project is in its design phase- to later provide the "before and after" and/or the "with and without" intervention comparisons.

The experimental or randomization approach is not without its critics. Some question its usefulness at the level of informing policy and strategy design altogether (Ravillion 2009). An obvious limitation is that typically the desire for 
undertaking an evaluation occurs when a project has already ended which makes the condition for randomization impossible. Another is the ethical question of excluding from treatment a control group when it involves welfare improving interventions. Other problems include: the limitations for scaling up to general equilibrium effects that occur at higher levels of impact but unaccounted for at the project level; the existence of uniquely defined local conditions which affect outcomes but are not always present in other locations; and, the observation that simply identifying 'what' worked from a project is not as useful for policy if it also does not answer 'why' it worked (Deaton 2009). Finally, its high costs may not always be justifiable, especially if they do not contribute much of anything to policy considerations. Weighing in the cost for experimental impact evaluations with the information expected from them should always be considered before undertaking such evaluations.

In most cases, non-experimental and practical alternatives are more suitable when projects are already underway. Among them are commonly accepted statistical and econometric techniques that compare outcomes between project participants and non-participants within a target population, such as controlling for observables, regression discontinuity design estimates, difference-in-differences and fixed effects approaches, as well as the use of instrumental variables (Duflo et al. 2008; Maredia 2009). In other cases, simple economic cost-benefit analysis (or rate of return studies) are just as useful, but only so long as there is sufficient underlying information on costs and behavioral assumptions associated with the project (see Gittinger 1984; Alston et al. 1995, 2000; and Masters et al. 1998).

The choice of economic tools ultimately depends on many factors: whether impact is being evaluated at the project or sector or economywide level; the type of questions being asked to ensure policy relevance; data availability and type; pre-existing models; resources and time available for analysis; and the capacity or skills of the evaluator. Ravillion (2008) offers some useful steps for evaluators to consider in selecting the most appropriate methods and approaches.

Finally, not all impact assessments are amenable to a quantitative set of economic analyses, such as projects that provide services or have a strong social dimension to them. Even when it is, other more qualitative social and political dimensions can also help explain impact. For example, collecting vital information about the social and political context, including the underlying policy landscape and processes, under which impact is being evaluated, can be particularly useful at answering questions about "why" and "how" a strategy or project may have failed or succeeded-rather than simply "what" caused it. In this context, the efficiency and effectiveness of program interventions and projects can also be evaluated.

Some examples of qualitative approaches for impact evaluation include rapid appraisal techniques (e.g. through civil society report cards), surveys of targeted beneficiaries to measure perceptions of impact (Maredia 2009; White 2006); use of impact pathway approaches to better understand processes and behavior; and the application of a sustainable livelihoods framework that considers a broader set of social and political explanations, in addition to the economic ones, in assessing a project's impact on welfare outcomes (Adato and Meinzen-Dick 2007). 
Unfortunately, the subjective nature of gathering information, including the lack of good statistical properties in validating results, often implies that the information generated and lessons learned are not always easily transferrable (Maredia 2009).

Given the range of approaches to developing an M\&E framework and ultimately assessing impact, the choice of what to use will always depend on: the agricultural strategy and corresponding range of policies and investments underlying it; the questions being asked; level of complexity in the known causal relationships; data availability, frequency, and type; existing tools; the skills of the analysts involved; the budget and costs allocated for M\&E; the time horizon for data collection and analysis; and individual country circumstances with regard to the social and political landscape and policy processes. With this knowledge, decisionmakers, technical analysts, and the key stakeholders involved, must together decide on which approach and what tools provide the most robust and cost effective M\&E for the particular agricultural strategy in mind. This is where the 'knowledge support system' concept and approach of SAKSS becomes more relevant.

\section{The Knowledge Support System Concept and Approach}

The 'knowledge support system' component of SAKSS describes a network of individuals and institutions that service the need for strategic analysis and information during the formulation and implementation of agricultural strategies. The network includes a range of individuals (researchers, policymakers, and development practitioners) and organizations (government agencies, research institutes, universities, development organizations, and private and civil society groups). These individuals and organizations are linked through this network under the shared interest of seeking tangible solutions to the challenges facing the agricultural sector.

Three core activities undertaken by the SAKSS network include collaborative strategic analysis, capacity strengthening, and dialogue. Through these activities relevant information from research findings and data analysis is compiled, synthesized, and packaged into evidence that enriches the dialogue on future agricultural priorities in a timely reliable fashion. The collaborative and participatory manner involved is intended to: help validate the relevant questions being asked by policymakers and civil society and the tools of analysis, data sources and assumptions, needed to address such questions; instill confidence in the evidence generated; and ultimately, enrich the capacity to generate and utilize analytical tools and evidence in the process of formulating and implement agricultural strategies.

Applications of this at the country and regional level exist. For example, a number of regional SAKSS nodes (or ReSAKSS) have focused much of their attention in mobilizing networks of individuals and organizations associated with the CAADP agenda at the regional level. Through these networks and a number of workshop forums, the nodes are helping to fill critical knowledge gaps, as well as bringing together a stock of knowledge, expertise, and tools, as countries begin to 
shape and align their agricultural strategies within the CAADP framework. A website brings together the information being collected to promote peer review across countries and updates on the progress of CAADP implementation (see www. resakss.org). The networks are in turn helping to establish country SAKSS nodes that are intended to strengthen a country's own ability to generate and provide strategic analysis, monitor key indicators, and assess impact of ongoing efforts against the principals and goals of CAADP.

\subsection{Linking Evidence with Policymaking}

The unknown question within an individual country's own social and political context is whether there is sufficient room to maneuver in order to bring evidence to bear in local policy processes during the formulation and implementation of their agricultural strategy. How research or evidence feeds into the policy process in developing countries is not yet fully understood. Yet, the importance of it so critical given the observation that many developing countries rely very little on scientificbased evidence when making policy decisions (Juma and Clark 1995). While there is a growing body of literature that seeks to explain the research-to-policy gap in Africa, few have come up with a testable hypothesis. Case study narratives are more common. The ongoing work by the International Development Research Centre (IDRC) in Canada and the Overseas Development Institute (ODI) in the UK are particularly noteworthy. Another team of researchers from Harvard University also offer a few African examples (see Cash et al. 2003).

The common accepted viewpoint in the African literature, as elsewhere in the world, is the observation that policymaking in general is a dynamic and complex process, sometimes simply explained as a chaos of purposes and accidents (Clay and Schaffer 1984). This is because the process involves multiple actors (individuals and organizations) which are defined by local political, social (cultural and belief systems), and institutional realities (bureaucratic structures and capacities). And being about people, vested interests among a few powerful elite, corruption, and external influences, can also play a distinctive role, as they still do in many African countries (Juma and Clark 1995). Power relations (people) and ideas (based on both tacit and explicit knowledge) are therefore particularly important. In fact, scientific knowledge often only plays a marginal role in the decisionmaking process (see Sabatier 2007).

Getting a good handle of a country's own policy process, and no matter its shortcomings, is therefore an important first step to understanding how evidencebased information can play any particular role in it. The question is not simply about how to improve the transfer of research into policy and vice versa, but more so about understanding the peculiar conditions under which links between the two can be made more effective.

Although various theoretical explanations of the policymaking process offer useful perspectives and frameworks on how research becomes embedded in the 
policy process, we do not cover this here but refer the reader to the expanded review in Johnson and Flaherty (2011). Here we focus more is describing how the 'knowledge support system' component of SAKSS is intended to help strengthen the links and capacities for greater evidenced-based dialogue and policymaking, while also ensuring quality in the evidence generated.

Essentially, the 'knowledge support system' component of SAKSS generally describes a network of individuals and organizations that effectively connect those who know with those who need to know. How effectively this helps to bring evidence into the policy process depends on how well the individuals in the network (both the actors who know and those who need to know) and the organizations they represent (e.g. research institutions, nongovernmental organizations, private organizations, and government agencies) are linked to promote dialogue around the knowledge products (i.e. information and results of research) and policy issues.

How the SAKSS network, in particular, can serve as a 'knowledge support system' in the context of an agricultural strategy is best illustrated using the Context Evidence and Links Framework developed by ODI (Crewe and Young 2002; Court and Young 2003). The framework involves four key elements: external influence, political context, evidence and links. It is appropriate for our purpose because it describes the complex interrelationships among a diverse group of actors, given a local political context and external environment, and thus the manner in which evidence can play a role in contributing to policymaking. Nevertheless, it should be underscored that the complexities of the research and policy interface cannot be adequately represented in a single framework as it involves many other dimensions. We only use it here for illustration purposes.

From Fig. 2 below, the processes and outcomes of the planning, implementation, and $M \& E$ activities are themselves greatly influenced by the interrelationships among the three spheres in the center, including the external environment surrounding them. Leadership and governance at the top emphasizes the principal role this plays in managing the agricultural strategy process itself, which is inherently influenced directly by the political context and external environment. Usually, the leader and manager of the agricultural strategy sits in the Ministry of Agriculture or other government agency/department charged with this responsibility. The biggest challenge for leadership and governance of the agricultural strategy is to improve the integration across all three activities-planning, implementation and M\&E. But also potentially influencing the outcome of this is the evidence that is being generated in the center, the links that influence the national debate, and the emergence of any changing political and socioeconomic realities. In other words, as new evidence becomes available (e.g. lack of progress or impact), or as socioeconomic and political realities change, or as new and emerging issues are brought to the forefront (e.g. via civil society groups, media), the priorities of the agricultural strategy may have to be altered.

Among the inner circles, the political context is the most critical as it describes the environment and process under which policies are made, and thus greatly affects how evidence plays any role in it (if at all). This includes factors such as political culture, extent of civil and political freedoms, vested interests, capacities 
of government to respond, and attitudes and incentives among officials (Young 2005). Here, the overlap of political context with evidence describes the process of "strategic analysis," drawing ideas and information from both government and the research community, past research, and the experience and knowledge of actors involved. How the two become more closely linked also depends on how well they both overlap with where 'the rubber hits the road'-the beneficiaries and interest groups of agricultural strategies, such as: development practitioners, farmers and trader groups, media, and civil society in general. On the other hand, the intersection between evidence and links can be viewed as one of discourse and dialogue (e.g. through publications, seminars, and media), while the one between the links and political context is more about advocacy (e.g. the world of campaigning and lobbying among local interest groups, media, and the broader electorate or civil society). Finally, the external environment, including the overall socioeconomic environment, as well as the influence of regional and international actors (e.g. donors), can be quite significant in the African context.

Effective linkages between evidence, dialogue, and policymaking are supposed to occur at the intersection of all three spheres, and it is here that evidence is expected to influence a policy change. The assumption is that when such links are established early enough, the evidence generated and discussed at this intersection is likely to be viewed as relevant and salient to the local context (Young 2005; Cash et al. 2003). The big challenge in most African countries is getting all three to intersect, given the poor state of evidence generation (from poor quality data, poor training and incentives, weak peer review systems), poor links (from poor communications, capacities), political context (power play, vested interests, top down bureaucracies, and elitist attitudes among officials), and external environment, especially the exaggerated influence of donors.

This is what the 'knowledge support system' component of a country SAKSS strives to achieve, in setting up an active network of key local actors (individuals and organizations) who intersect from all three spheres. Through extensive consultations and interactions in the network, activities involving strategic analysis, capacity strengthening, and dialogue are laid out. The scope of work under each of these activities draws on the active input of all stakeholders: local research partners and analysts (evidence), key government actors and agencies (political context), and stakeholder groups (links).

\subsection{Supporting CAADP Implementation}

The SAKSS concept was adopted in 2006 to support CAADP and its principles for promoting progress review at country level, peer review at the regional level, and mutual review at the continental level. This has involved establishing three regional SAKSS nodes (or ReSAKSS) in each of the major regional economic communities (RECs): Common Market for Eastern and Southern Africa (COMESA), Economic Community of West Africa States (ECOWAS), Southern Africa Development 
Community (SADC). The ReSAKSS nodes are hosted and led by the International Institute of Tropical Agriculture (IITA) in Ibadan, Nigeria for West Africa; by the International Livestock Research Institute (ILRI) in Nairobi, Kenya for Eastern and Central Africa; and by the International Water Management Institute (IWMI), with the International Crops Research Institute for the Semi-Arid Tropics (ICRISAT), in Pretoria, South Africa for Southern Africa. IFPRI is helping to coordinate a common agenda across the three nodes, providing technical and analytical support, and helping maintain and strengthen links with a broad network of CAADP partners. An Africa-wide steering committee provides overall oversight to ensure the ReSAKSS agenda remains relevant and useful in supporting CAADP implementation.

Generally, the ReSAKSS nodes focus their activities in three main areas: Strategic analysis, Knowledge management and communications, and Capacity strengthening. The strategic analysis activities help fill critical knowledge gaps in assessing progress toward realizing the CAADP goals of allocating $10 \%$ of the national budget to agriculture, achieving a $6 \%$ annual agricultural growth rate, and meeting the first MDG of halving poverty and hunger by 2015 . As part of this, the ReSAKSS helped develop a monitoring and evaluation (M\&E) framework for CAADP (see Benin et al. 2010).

Under the knowledge management and communications component, ReSAKSS and its network of partners collect data on key indicators such as public spending; integrating and building upon existing data, analytical tools, and knowledge; and facilitating timely access of the knowledge by African policymakers and development partners to allow for more evidence-based decisionmaking. To this end, ReSAKSS has launched a website to share the information it generates and compiles, on these key indicators and on ARD in general (see www.resakss.org).

A number of country level analyses were also undertaken by ReSAKSS to inform country CAADP Roundtables involving Rwanda, Malawi, Kenya, Uganda, and Zambia in 2006 and 2007, and a number of West Africa countries in 2008. The results served as critical input into the stakeholder dialogue and preparations leading up to the signing of a CAADP Roundtable compact within each country (as Fig. 1 previously illustrated). Further support was also provided in helping inform each country's investment plans during the post-CAADP compact period. By the end of 2011, according to the online ReSAKSS Newsletter (resakss. wordpress.com), 22 countries had signed their country CAADP compacts, 18 have developed national agricultural investment plans, and 15 countries have held their technical reviews, out of which five (Ethiopia, Niger, Rwanda, Sierra Leone and Togo) received a total of \$223.5 million from the Global Agriculture and Food Security Program (GAFSP) fund. Other countries continue to sign on to the CAADP framework, including Mozambique, which just formally launched the process on December 13th. Djibouti is the most recent country to sign on in 2012.

In 2010, ReSAKSS began a second phase of its support to CAADP implementation. Much of its activities have been have been focused on consolidating ReSAKSS as a leading knowledge platform for agricultural policy planning and implementation in Africa, more fully operationalizing the CAADP monitoring and 


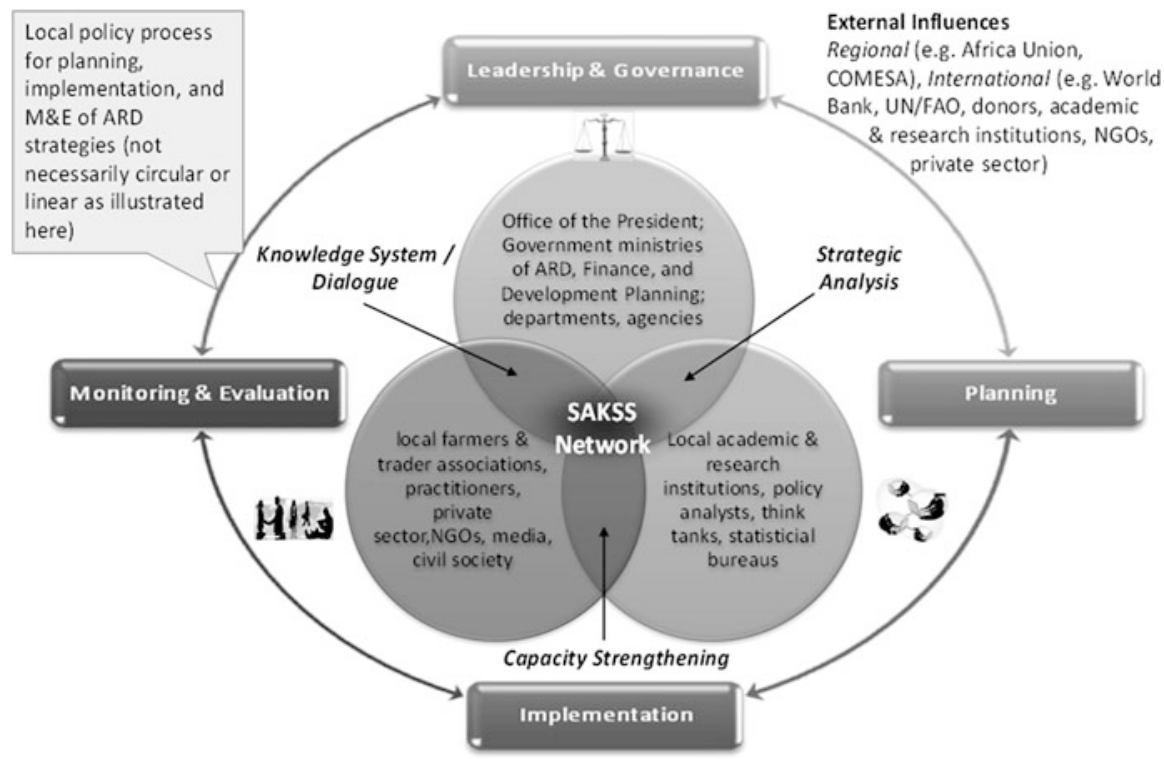

Fig. 3 The ‘knowledge support system’ framework. Source: Johnson and Flaherty (2011)

evaluation (M\&E) system it helped develop at the country level, and providing technical assistance for the establishment of country SAKSS nodes. Because CAADP is meant to be implemented at the country level according to a country's own compacts and investment plans, a goal of the M\&E system is to not only help strengthen country capacities for monitoring progress and assessing impact through their SAKSS network of partners, but ensure the adoption of standardized and measurable indicators that are consistent across different countries and regions to facilitate cross-country peer review and mutual learning.

Figure 3 provides a schematic diagram which describes the M\&E system of CAADP as set up by the ReSAKSS. Developed around a theoretical framework that is described in more detail in Benin et al. (2010), the system uses a number of indicators to monitor progress of CAADP implementation: inclusive of process, policy, investment and outcome indicators being targeted at all three levels - country, regional and continental. Several important processes associated with CAADP implementation include the signing of CAADP compacts, finalizing investment plans and resource commitments. Other important milestones in the process include tracking and assessing the sorts of policy and strategic issues being raised through stocktaking exercises, reviewing the plans to address them, and assessing the roles of different stakeholders and their capacities to provide and utilize the knowledge.

In many cases, for example, capacity gaps may need to be filled through the provision of appropriate skills training and mentoring for undertaking $M \& E$ and policy analysis. These milestones, among others, are represented by the eight circular steps in the country CAADP implementation process at the bottom of the 


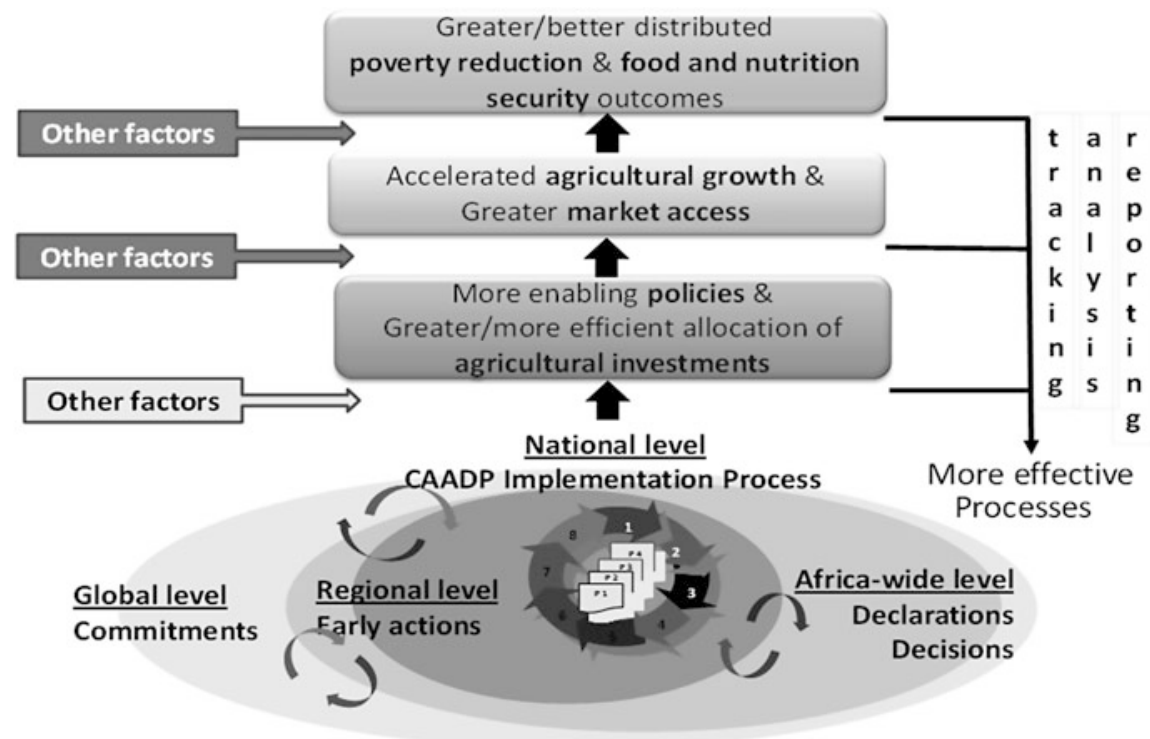

Fig. 4 Supporting the M\&E of the CAADP implementation process. Source: Sam Benin, ReSAKSS slide presentation of support to CAADP M\&E, 2011

figure. These help lead to increased and more efficient allocation of resources, and in turn, outputs and outcomes (Fig. 4).

The full operationalization of the CAADP M\&E system is going to depend a lot on the establishment of country SAKSS nodes, particularly in those countries that have signed their country compacts and validated their investment plans. The generic setup of a country SAKSS node is intended to strengthen the capacities of national knowledge systems to undertake their own strategic analysis, $M \& E$, and in promoting greater evidenced-based decisionmaking. A secretariat is best hosted by a local institution in order to serve the primary function of supporting its country's own need for reviewing progress of CAADP implementation. As a member of the ReSAKSS network of partners, the node is able to draw on a wide range of expertise and knowledge, as well as contribute to the ReSAKSS regional and continental efforts for CAADP M\&E. Figure 5 below illustrates the generic structure of a country SAKSS node, showing the relationships between the SAKSS secretariat, in country key stakeholders, funding sources (government and development partners), and links with the broader ReSAKSS network.

\subsection{Ensuring Effective Knowledge Support Systems}

The process of establishing the ReSAKSS and country SAKSS nodes in support of CAADP implementation has relied on a number of practical principles that serve to 


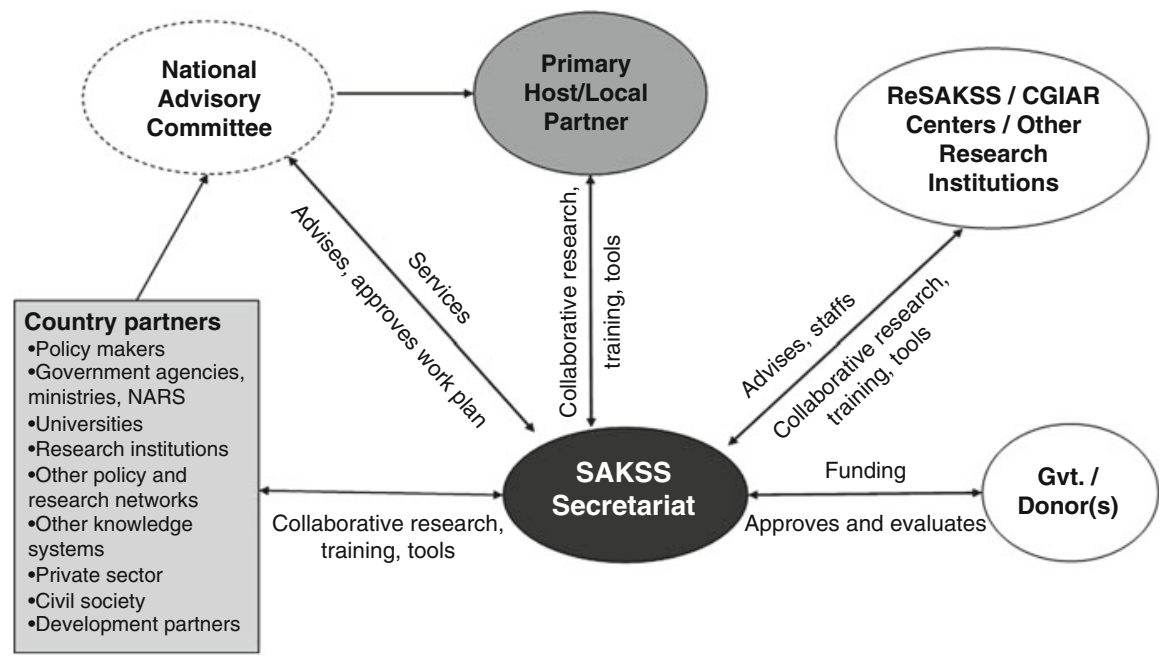

Fig. 5 A generic country SAKSS node. Source: Johnson and Flaherty (2011)

ensure an effective "knowledge support system" among its networks of partners. ${ }^{2}$ These have been distilled from both literature surveys and IFPRI's own experiences to date with the setup of several 'country strategy support programs' in Africa; including principles of participation and collaboration, flexibility, high level dialogue and brokering, credibility and legitimacy, sustainability, and capacity strengthening.

\subsubsection{Participation and Collaboration}

From the beginning, the establishment of a country SAKSS node should be countryowned and driven, and its processes participatory and transparent. For example, any 'strategic analysis' and knowledge management activities should be undertaken in a collaborative manner to promote local involvement and ownership. This ensures that the evidence generated is both relevant and salient to the perspectives, concerns, and issues, of both local researchers as 'suppliers' and policymakers and their stakeholders as 'users,' and thus increasing the chances of policy impact (Cash et al. 2003; Court and Young 2003; Ryan and Garrett 2003; Wangwe 2005).

\footnotetext{
${ }^{2}$ While we only focus on the principles here, practical steps on how to go about setting up a country SAKSS node are discussed in more detail in Johnson and Flaherty (2011).
} 


\subsubsection{Flexibility}

Because there is no 'one-size-fits-all' development model, SAKSS should always remain flexible enough to adapt to different country conditions involving institutional capacity and political context, especially as it relates to the ongoing process of strategy design and implementation. The structure of the programs and networks established must also be allowed to vary, depending on existing stock of institutional capacity and knowledge, political context of government and donor relations, level and source of funding, and awareness of the value of scientific evidence for policymaking.

\subsubsection{High Level Dialogue and Brokering}

Policymakers must be actively involved in helping to review and laying out the scope of work of a SAKSS node in their own country. There should be room for close overlaps between researchers/analysts and policymakers to ensure attention is paid to continuous dialogue by analysts and researchers with key policymakers, executive government officials, as well as parliamentarians. The degree of proximity of outside research institutions to in-house policy analysis units (e.g. within legislative and executive branches of government) has been found to have an important effect on how well research results are communicated and received by policymakers (Ryan 1999). At the same time, the existence of close, personal links between individuals (researchers and policymakers) can also be just as effective (Court and Young 2003; Timmer 1998). A potential disadvantage is when too close a relationship marginalizes the contributions of other researchers and research institutions, limiting the diversity of views to which policymakers have access (Stone et al. 2001).

\subsubsection{Credibility and Legitimacy}

Knowledge systems and formal knowledge networks should be structured in a way that adheres to the same criteria for credibility and legitimacy that is applied to policy research (Cash et al. 2003). Knowledge networks are credible when the participants represent shared and common institutional mandates rather than personal research interests. The degree of credibility is only enhanced when membership is limited to those institutions with a strong local reputation for their expertise and for their capacity to influence the policy process (Ryan and Garrett 2003).

Depending on the current state of a country's own capacity for policy analysis and research, it may be necessary to rely on foreign experts and institutions, but close links must be established with a local institutions and individuals who have the respect of the domestic policy-making community. They not only offer critical local knowledge, but are more cognizant to domestic policy concerns, and may also be viewed as being less ideologically driven as foreign institutions (Jayne et al. 
1999; Wangwe 2005). On the other hand, foreign institutions can provide a basis for enhancing the credibility of the research, bringing in better access to international research resources and standards, as well as on-the-job learning, to strengthen domestic research capacity (Jayne et al. 1999). If sustained over the long term, together with sufficient higher degree training, such efforts can go a long way in promoting and sustaining a think tank culture that effectively influences national dialogue and decisionmaking about future policies and strategies.

\subsubsection{Sustainability}

Policy research and analysis capacity have to be built incrementally and sustainably, which means ongoing support for key government policy agencies as well as encouragement of a think-tank culture for producing high quality, policy relevant research products. Therefore, countries ultimately need to have ownership of SAKSS from the beginning to enable its principals and tools to become institutionalized within local government agencies and research institutions over time. To accomplish this, both in-country researchers (as suppliers) and stakeholders (as end-users) need to be actively engaged early on to commit to a long-term institutionalization process that involves knowledge synthesis and generation, compiling lessons from 'learning by doing,' institutional arrangements or platform for linking research to policy, and human and institutional capacity strengthening.

\subsubsection{Capacity Strengthening}

The SAKSS concept is founded on the recognition that many developing countries lack the capacity to generate reliable research-based information and analysis needed to inform and guide development strategies. Therefore, strengthening the capacity of countries to provide much needed credible information and knowledge systems for strategy development and implementation must be integral to the ongoing activities of a country SAKSS node. The core assumption is that as relevant and timely information is increasingly provided from local sources to the policy dialogue and design of strategies in each region, a greater appreciation and reliance on empirical evidence would emerge and lead to sustained improvements in sector governance and policy impact over time. A SAKSS node, therefore, must play a catalytic role in developing a capacity strengthening strategy that promotes and improves the capacities of local partner institutions best placed to undertake 'strategic analysis' and bring evidence to bear during dialogue and deliberations about future development priorities.

Finally, the success of country SAKSS nodes, especially in their role as 'knowledge support systems' will ultimately depend a lot on how well they are able to establish strong ties across a diverse group of actors in their networks-throughout the process of generating credible evidence, sharing the evidence, and promoting dialogue around the evidence. It will also depend on how well they are able to understand the policy landscape and overall external influences at play within their 
respective countries and regions, and how they are eventually perceived by their network of partners based on the type of activities it supports and the evidence they generate.

\section{Conclusion}

The SAKSS concept was developed to provide a framework by which the gaps between evidence and policymaking can be narrowed through the application of 'strategic analysis' and 'knowledge support systems' approaches designed to inform and strengthen the effectiveness of agricultural strategies in Africa, and in particular, CAADP implementation. The chapter has provided a broad overview of the SAKSS concept, a review on the type of 'strategic analyses' it seeks to address, the kind of tools and approaches needed to ensure effective 'knowledge support systems' that promote evidenced-based dialogue and decisionmaking, and a guide on how to go about setting up such systems at country level.

The application of SAKSS in support of CAADP at the country (via country SAKSS nodes) and regional (via the ReSAKSS nodes) is allowing for lessons to be drawn and thus improve our understanding of how such systems can be made more effective in helping to bring evidence to bear during policy dialogue and decisionmaking processes. While it is still too soon to determine the success of these systems without a more detailed comparative analysis, especially if it can be derived from an external and independent evaluation, certain lessons and principles have emerged over time from the experiences of IFPRI in establishing the ReSAKSS and several 'country strategy support programs' in Africa. We summarize some of these here.

- Local partners must shape the relevance of a SAKSS: Key partner organizations (e.g. research institutions, government ministries, universities, and NGOs) must perceive and be engaged to help fashion its relevance and utility. Only through such levels of institutional engagement will SAKSS be able to provide improved and commonly accepted approaches that can foster, enhance, and improve synergies among the varied and multiple development efforts. Dialogue with the local policymakers, analysts, and existing networks is essential at the early stages to determine the local needs and capacity.

- Adapts to local conditions: It must be able to be institutionalized and maintained in ways that enable it to adapt to local conditions and serve as a national and regional public resource.

- Maintains broad representation of stakeholders: Its organizational and governance structure must be established in a way that allows a broad representation of key stakeholders (government, university, think tanks, development practitioners, civil society, farmer organizations, and development partners) to maintain its relevance.

- Establishes strong links with a local partner(s): It must be able to develop strong links with local partner institutions and organizations to help strengthen their 
capacities to provide and sustain the SAKSS in the long run. Strong ties with local partner institutions and government bodies help maintain the relevance of a SAKSS program as country-led and owned.

- Produces collaborative quality products: The ability to maintain quality products that have been produced in close collaboration with network partners and institutions raises the credibility of the program while maintaining its relevance and utility among partners and stakeholders.

- Has a local champion: The presence of an active champion within the Steering Committee helps to establish stronger ties among the network data and analysis suppliers, as well as the relevance of its outputs among users (e.g. government agencies, policymakers, development partners).

- Inherits multiple donor support: The existence of multiple donors and a sufficient level of resources strengthen the perception of SAKSS as a general public good in support of local interests and capacity needs.

- Build credibility and trust among competing partners: A SAKSS network is not the only player in providing strategic analysis and information for informing agricultural strategies. It is therefore important to maintain a degree of transparency in reaching out to other experts who may have comparative advantage in a particular area. A SAKSS should utilize this expertise with sufficient incentive structures in place for collaboration. This could also be done in the form of organizing seminars to encourage broader participation by experts outside the network. SAKSS should refrain from giving the impression its network of partners has sufficient expertise in all areas.

Of course there is no single blueprint of a country SAKSS. The experience of existing programs highlights the unique conditions that exist within each country with respect to stakeholder needs, human and institutional capacity, current stock of knowledge, funding levels, data availability and quality, and existing relationships between government, donors, and the research community. We also emphasized the many factors that can influence the effectiveness of a SAKSS for promoting evidence-based dialogue and decisionmaking, including the political context, external influence, and relationships among individual champions and their organizational links. These ultimately shape the SAKSS each country with respect to its governance and institutional structure, relationships with local partners, and analytical agenda, for instance. Despite these differences, however, we laid out some basic principles, definitions, and objectives underlying the SAKSS concept and the process of establishing a country SAKSS. We also offered a step-by-step guideline for setting it up, drawing on the experience of existing efforts and lessons from the literature.

Finally, the operational aspects of SAKSS offer a real world opportunity to test the concept and its principles. For example, certain institutional and political economy issues, including individual and organizational interactions, emerge out of the collaboration and networking inherent in a SAKSS. From this, a number of important questions arise-what drives the interactions in such networks? What factors constrain their ability to function well (such as incentives, institutional affiliations and tensions, transaction costs, competitiveness, different underlying 
development paradigms, values, and approaches)? Does the type of membership mix in the networks affect the credibility of the analysis? Other challenging questions that can also arise and worth exploring further include-how can a SAKSS balance the supply of credible information (which is limited) with its demand (which is almost endless)? Can those who seek the information most also pay for it? If not, what are the tradeoffs for accepting external donor involvement and influence?

\section{References}

Adato, M., and R. Meinzen-Dick, eds. 2007. Agricultural research, livelihoods and poverty: Studies of economic and social impact in six countries. Baltimore, MD: Johns Hopkins University Press.

Alston, J.M., G.W. Norton, and P.G. Pardey. 1995. Science under scarcity. Ithaca, NY: Cornell University Press.

Alston, J. M., T. J. Wyatt, P. G. Pardey, M. C. Marra, and C. Chan-Kang. 2000. A meta-analysis of rates of return to agricultural R\&D: Ex Pede Herculem? IFPRI Research Report 113. Washington, DC: International Food Policy Research Institute.

Anderson, E., P. de Renzio, and S. Levy. 2006. The role of public investment in poverty reduction: Theories, evidence and methods. ODI Working Paper 263. London, UK: Overseas Development Institute.

AU/NEPAD (Africa Union/New Partnership for Africa's Development). 2005. Guidance note for agriculture expenditure tracking system in African countries. Midrand: African Union (AU) and New Partnership for Africa's Development (AU/NEPAD).

Babu, S.C., and P. Pinstrup-Andersen. 1994. Food security and nutrition monitoring: A conceptual framework, issues and challenges. Food Policy 19 (6): 218-233.

Bell, C., P.B.R. Hazell, and R. Slade. 1982. Project evaluation in regional perspective. Baltimore, MD: Johns Hopkins University Press.

Benin, S., M. Johnson, B. Omilola, and the Technical Working Group (TWG) Members. 2010. Monitoring and evaluation $(M \& E)$ system for the comprehensive Africa agriculture development programme $(C A A D P)$. ReSAKSS Working Paper 6. Washington, DC, USA: Regional Strategic Analysis and Knowledge Support System, facilitated by the International Food Policy Research Institute.

Benin, S., J. Thurlow, X. Diao, C. Lungren, and F. Simtowe. 2008a. Agricultural growth and investment options for poverty reduction in Malawi. IFPRI Discussion Paper 794. Washington, DC: International Food Policy Research Institute.

Benin S., A. Nin Pratt, S. Fan, C. Breisinger, T. Mogues, J. Thurlow, and X. Diao. 2008b. Growth and poverty reduction impacts of public investments in agriculture and rural areas: Assessment techniques, tools and guide for practitioners. ReSAKSS Working Paper 7. Washington, DC: Regional Strategic Analysis and Knowledge Support System, facilitated by the International Food Policy Research Institute.

Bolwig, S., P. Hazell, and S. Wood. 2002. Strategic assessment of land use options for UgandaStrategic criteria for rural investment in productivity (SCRIP) phase I. Project document. Washington, DC: International Food Policy Research Institute.

Brinkerhoff, D. 1996. Process perspectives on policy change: Highlighting implementation. World Development 24 (9): 1395-1401.

Byerlee, D. 2000. Targeting poverty alleviation in priority setting for agricultural research. Food Policy 25: 429-445. 
Cash, D.W., W.C. Clark, F. Alcock, N.M. Dickson, N. Eckley, D.H. Guston, J. Jager, and R.B. Mitchell. 2003. Knowledge systems for sustainable development. Proceedings of the National Academy of Sciences 100 (14): 8086-8091.

Chamberlin, J., J. Pender and B. Yu. 2006. Development domains for Ethiopia: Capturing the geographical context of smallholder development options. DSGD Discussion Paper 43. Washington, DC: International Food Policy Research Institute.

Clay, E., and B. Schaffer, eds. 1984. Room for maneuver: An exploration of public policy in agriculture and rural development. London: Heinemann.

Court, J., and J. Young. 2003. Bridging research and policy: Insights from 50 case studies. Working Paper 213. London: Overseas Development Institute.

Crawford, P., and P. Bryce. 2003. Project monitoring and evaluation: A method for enhancing the efficiency and effectiveness of aid project implementation. International Journal of Project Management 21: 363-373.

Crewe E., and J. Young. 2002. Bridging research and policy: Context, evidence and links. ODI Working Paper 173. London: Overseas Development Institute.

Crosby, B. 1996. Policy implementation: The organizational challenge. World Development 24 (9): 1403-1415.

Dalal-Clayton, B., and S. Bass. 2002. Sustainable development strategies: A resource book. London: Earthscan Publications.

Deaton, A. 2009. Instruments of development: Randomization in the tropics, and the search for the elusive keys to economic development. Mimeo. Princeton, NJ: Princeton University, Center for Health and Wellbeing, Research Program in Development Studies.

Dorotinsky, B., and R. Floyd. 2004. Public expenditure accountability in Africa: Progress, lessons and challenges. In Building state capacity in Africa: New approaches, emerging lessons, ed. B. Levy and S. Kpundeh, 179-210. Washington, DC: The World Bank.

Dorward, A., J. Kydd, J. Morrison, and I. Urey. 2004. A policy agenda for pro-poor agricultural growth. World Development 32 (1): 73-89.

Douthwaite, B., T. Kuby, E. van de Fliert, and S. Schulz. 2003. Impact pathway evaluation: An approach for achieving and attributing impact in complex systems. Agricultural Systems 78: 243-265.

Duflo, E., R. Glennerster, and M. Kremer. 2008. Using randomization in development economics research: A toolkit. In Handbook of development economics, ed. T.P. Schultz and J. Strauss, vol. 4, 3895-3962. Amsterdam: North Holland.

Earl, S., F. Carden, and T. Smutylo. 2001. Outcome mapping: Building learning and reflection into development programs. Ottawa, ON: International Development Research Centre.

Fan, S., M. Johnson, A. Saurkar, and T. Makombe. 2008. Investing in African agriculture to halve poverty by 2015. IFPRI Discussion Paper 751. Washington, DC: International Food Policy Research Institute.

Fan, S., X. Zhang, and N. Rao. 2004. Public expenditure, growth, and poverty reduction in rural Uganda. DSGD Discussion Paper 4. Washington, DC: International Food Policy Research Institute.

Farrington, J., C. Thirtle, and S. Henderson. 1997. Methodologies for monitoring and evaluating agricultural and natural resources research. Agricultural Systems 55 (2): 273-300.

Gittinger, J.P. 1984. Economic analysis of agricultural projects. EDI series in economic development. Washington, DC and Baltimore, MD: The World Bank and Johns Hopkins University Press.

Jayne, T.S., M. Mukumbu, M. Chisvo, D. Tschirley, M.T.Weber, B. Zulu, R. Johannson, P. Santos, and D. Soroko. 1999. Successes and challenges of food market reform: Experiences from Kenya, Mozambique, Zambia, and Zimbabwe. MSU International Development Working Paper 72. East Lansing, MI: Michigan State University, Department of Agricultural Economics. 
Johnson, M., R. Birner, J. Chamberlin, X. Diao, S. Fan, A. Nin-Pratt, D. Resnick, L. You and B. Yu. 2008. Regional strategic alternatives for agriculture-led growth and poverty reduction in West Africa. ReSAKSS Working Paper 22. Washington, DC: Regional Strategic Analysis and Knowledge Support System, facilitated by the International Food Policy Research Institute.

Johnson, M. and K. Flaherty. 2011. Strategic analysis and knowledge support systems for agriculture and rural development in Africa: Translating evidence into action. Food Security in Practice No.6, Washington, DC: International Food Policy Research Institute.

Juma, C., and N. Clark. 1995. Policy research in sub-Saharan Africa: An exploration. Public Administration and Development 15: 121-137.

Killick, T. 1976. The possibilities of development planning. Oxford Economic Papers 28 (2): 161-184.

Kiregyera, B. 2008. Reforming national statistical systems in Africa: A case for making the National Statistics Offices autonomous. Addis Ababa: United Nations Economic Commission for Africa, African Centre for Statistics.

Kusek, J.Z., and R.C. Rist. 2004. Ten steps to a results-based monitoring and evaluation system: A handbook for development practitioners. Washington, DC: The World Bank.

Mackay, K. 2007. How to build M\&E systems to support better government. Washington, DC: The World Bank.

Maredia, M.K. 2009. Improving the proof - Evolution of and emerging trends in impact assessment: Methods and approaches in agricultural development. Background Paper prepared for the 'Millions Fed Project'. Washington, DC: International Food Policy Research Institute.

Masters, W., T. Bedingar, and J. Oehmke. 1998. The impact of agricultural research in Africa: Aggregate and case study evidence. Agricultural Economics 19: 81-86.

Minot, N., and B. Baulch. 2005. Poverty mapping with aggregate census data: What is the loss in precision? Review of Development Economics 9 (1): 5-24.

Montjoy, R., and L. O'Toole. 1979. Toward a theory of policy implementation: An organizational perspective. Public Administration Review 39 (5): 465-476.

Omamo, S.W. 2004. Bridging research, policy, and practice in African agriculture. DSGD Discussion Paper 10. Washington, DC: International Food Policy Research Institute.

Omamo, S., X. Diao, S. Wood, J. Chamberlin, L. You, S. Benin, U. Wood-Sichra, and A. Tatwangire. 2006. Strategic priorities for agricultural development in Eastern and Central Africa. IFPRI Research Report 150. Washington, DC: International Food Policy Research Institute.

Pender, J., P. Jagger, E. Nkonya, and D. Sserunkuuma. 2001. Development pathways and land management in Uganda: Causes and implications. EPTD Discussion Paper 85. Washington, DC: International Food Policy Research Institute.

Ravillion, M. 2008. Evaluation in the practice of development. Policy Research Working Paper 4547. Washington, DC: The World Bank.

2009. Should the randomistas rule? The Economists' Voice 6 (2): 1-5.

Ryan, J.G. 1999. Assessing the impact of policy research and capacity building by IFPRI in Malawi. Impact Assessment Discussion Paper 11. Washington, DC: International Food Policy Research Institute.

Ryan, J.G., and J.L. Garrett. 2003. The impact of economic policy research: Lessons on attribution and evaluation from IFPRI. Impact Assessment Discussion Paper 20. Washington, DC: International Food Policy Research Institute.

Sabatier, P., ed. 2007. Theories of the policy process. 2nd ed. Boulder, CO: Westview Press.

Smutylo, T. 2005. Outcome mapping: A method for tracking behavioral changes in development programs. ILAC Brief 7. Rome: Institutional Learning and Change Initiative.

Springer-Heinze, A., F. Hartwich, J. Henderson, D. Horton, and I. Minde. 2003. Impact pathway analysis: An approach to strengthening the impact orientation of agricultural research. Agricultural Systems 78: 267-285. 
Stone, D., S. Maxwell, and M. Keating. 2001. Bridging research and policy. Sussex, UK: Radcliffe House, Warwick University.

Thurlow, J., S. Benin, X. Diao, A. Kebba, and N. Ofwono. 2008a. Agricultural growth and investment options for poverty reduction in Uganda. IFPRI Discussion Paper 790. Washington, DC: International Food Policy Research Institute.

Thurlow, J., S. Benin, X. Diao, H. Kalinda, and T. Kalinda. 2008b. Agricultural growth and investment options for poverty reduction in Zambia. IFPRI Discussion Paper 791. Washington, DC: International Food Policy Research Institute.

Timmer, C. P. 1998. Adding value through policy-oriented research: Reflections of a scholarpractitioner. Impact Assessment Discussion Paper 4. Washington, DC: International Food Policy Research Institute.

Wangwe, S. 2005. A review of how external agencies can influence research agendas and research policy links. Mimeo. Dar-es-Salaam: Economic and Social Research Foundation.

White, H. 2006. Impact evaluation: The experience of the independent evaluation group of the World Bank. MPRA Working Paper 1111. Washington, DC: The World Bank

Wildavsky, A. 1973. If planning is everything, maybe it's nothing. Policy Sciences 4: 127-153.

Wingfield-Digby, P. 2007. Towards reforming National Statistical Agencies and Systems: A survey of best practice countries with effective National Statistical Systems in Africa. Harare: African Capacity Building Foundation.

Wood, S., and J. Chamberlin. 2003. Enhancing the role of spatial analysis in strategic impact assessment: Improving data resolution for regional studies. Quarterly Journal of International Agriculture 42 (2): 167-187.

Wood, S., K. Sebastian, F. Nachtergaele, D. Nielsen, and A. Dai. 1999. Spatial aspects of the design and targeting of agricultural development strategies. EPTD Discussion Paper 44. Washington, DC: International Food Policy Research Institute.

World Bank. 2004. Monitoring and evaluation: Some tools, methods and approaches. Washington, DC: The World Bank.

You, L., S. Wood, U. Wood-Sichra, and J. Chamberlin. 2007. Generating plausible crop distribution maps for sub-Saharan Africa using a spatial allocation model. Information Development $23(2 / 3): 151-159$.

Young, J. 2005. Research, policy and practice: Why developing countries are different. Journal of International Development 17: 727-734.

Michael E. Johnson is Director of Research in the Food and Nutrition Security Unit at CARE USA. Previously, he was a Senior Research Fellow in the Development Strategy and Governance Division at IFPRI where he conducted research on various topics including technology adoption and spillovers, knowledge systems and policy process, agro-industry and value chains, and input markets. His contribution to this book is based on the research he undertook while he was at International Food Policy Research Institute (IFPRI).

Open Access This chapter is licensed under the terms of the Creative Commons Attribution 4.0 International License (http://creativecommons.org/licenses/by/4.0/), which permits use, sharing, adaptation, distribution and reproduction in any medium or format, as long as you give appropriate credit to the original author(s) and the source, provide a link to the Creative Commons license and indicate if changes were made.

The images or other third party material in this chapter are included in the chapter's Creative Commons license, unless indicated otherwise in a credit line to the material. If material is not included in the chapter's Creative Commons license and your intended use is not permitted by statutory regulation or exceeds the permitted use, you will need to obtain permission directly from the copyright holder.

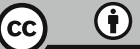

